\title{
Evaluating the behaviour of vertical structure indices in Scots pine forests
}

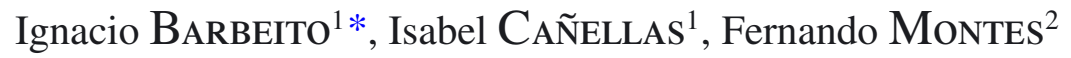 \\ ${ }^{1}$ CIFOR-INIA, Ctra. La Coruña, km 7,5, 28040 Madrid, Spain \\ ${ }^{2}$ Departamento de Silvopascicultura. Universidad Politécnica de Madrid, Ciudad Universitaria s/n, 28040 Madrid, Spain
}

(Received 10 April 2008; revised version 14 August 2008; accepted 2 March 2009)

Keywords:

diversity index /

height distribution /

spatial heterogeneity /

stand structure
Mots-clés :

indice de diversité /

distribution des hauteurs /

hétérogénéité spatiale /

structure des peuplements

\begin{abstract}
- Stand structure indices would appear to be good surrogate measures for biodiversity in forest ecosystems.

- The vertical structure of Pinus sylvestris L. stands in Central Spain was analysed in order to evaluate their structural diversity. A comparison between two forests with similar ecological conditions but managed under different silvicultural systems was conducted in order to analyse changes in diversity at different stages of stand development. Height diversity was quantified using two non-spatially explicit indices (Shannon's index and STVI) as well as two spatially explicit indices (Gadow's differentiation index and the Structure complexity index). A new diversity index was then proposed, based on the sum of square roots of height differences (SQRI).

- Correlations between all vertical structure indices were highly significant. All indices showed that height diversity was greater in the forest with the longer regeneration period and where less intensive thinnings were applied throughout the rotation. Diversity was highest in uneven-aged stands and in the period between the regeneration stage and the first thinning. Thinning from below accounted for the decrease in vertical structure complexity throughout the rotation in even-aged stands.

- The results show that height distribution along with successional stage data enhance the analysis of vertical diversity since structural complexity is highly related to the silvicultural practices that are carried out at different ages.
\end{abstract}

Résumé - Évaluer le comportement des indices de structure verticale dans les forêts de pin sylvestre.

- Les indices de structure de peuplements semblent être de bonnes mesures de substitution pour l'estimation de la biodiversité dans les écosystèmes forestiers.

- La structure verticale des peuplements de Pinus sylvestris L. dans le centre de l'Espagne a été analysée afin d'évaluer leur diversité structurelle. Une comparaison entre deux forêts, ayant des conditions écologiques similaires mais gérées avec une sylviculture différente, a été réalisée afin d'analyser les changements dans la diversité à différents stades de développement du peuplement. La diversité de hauteur a été quantifiée au moyen de deux indices non-spatialement explicites (indice de Shannon et STVI) ainsi que de deux indices spatialement explicites (l'Indice de différenciation Gadow et l'Index de complexité de structure). Un nouvel indice de la diversité, basé sur la somme des carrés des racines des différences de hauteur (SQRI), a ensuite été proposé.

- Les corrélations entre les indices de structure verticale sont très significatives. Tous les indices montrent que la diversité en hauteur est plus grande dans la forêt ayant la plus longue période de régénération et là où les éclaircies les moins intensives ont été appliquées dans l'ensemble de la rotation. La diversité est la plus élevée dans les peuplements inéquiennes et dans la période entre la phase de régénération et la première éclaircie. L'éclaircie par le bas représente la diminution de complexité de la structure verticale dans l'ensemble de la rotation, dans les peuplements équiennes.

- Les résultats montrent que la distribution des hauteurs avec les données des stades de succession améliore l'analyse de la diversité verticale puisque la complexité structurelle est fortement liée à la sylviculture qui a été réalisée à des âges différents.

\footnotetext{
*Corresponding author: barbeito@inia.es
} 


\section{INTRODUCTION}

One of the challenges in forest planning today is understanding how current management affects biodiversity. Structural diversity indices of a stand may be used to quantify biodiversity. Vertical and horizontal positioning, mixture, and age distribution have been shown to affect avian, insect and herbaceous plant diversity (Berger and Puettmann, 2000; Degraaf et al., 1998; MacArthur and MacArthur, 1961; Moen and Gutiérrez, 1997; Recher et al. 1996) and thus structural diversity can be used to indicate overall species diversity (Kimmins, 1997). Furthermore, stand structural diversity offers the advantage of being more easily measurable in the field compared to species diversity. The vertical structure of forest ecosystems depends on the intra and inter-specific competition, shade tolerances of species, site conditions and disturbance regimes, and its use in quantifying forest biodiversity is widely acknowledged (MacArthur and MacArthur, 1961; North et al., 1999). Similarly, spatial pattern has been extensively studied in plant ecology because it reflects underlying biological processes such as reproductive and dispersal behaviour, competition, response to the environment, disturbance and site history (Dale, 1999; Miller et al., 2002), giving insights into species ecology.

A variety of spatial diversity indices have been increasingly used to compare alternative management approaches (Neumann and Starlinger, 2001). One of the most widely used methods to assess the vertical structure diversity involves calculating the Shannon index (Shannon, 1949) with the foliage distribution in vertical strata (foliage height diversity index, FHD) (MacArthur and MacArthur, 1961). The FHD requires a specific sampling method to asses the vertical arrangement of the vegetal layers (Ferris-Kaan et al., 1998), which may not be a straightforward process if these layers are not well defined. Some authors have employed the Shannon diversity index using diameter or height classes (Buongiorno et al., 1994; Staudhammer and LeMay, 2001) However, the choice of classes greatly influences the FHD value; therefore other methods have been developed. Diversity indices based on the variance, for example STVI (Staudhammer and LeMay, 2001) seem to be preferable for continuous variables such as tree height. Methods that include data on tree position to characterize the vertical diversity at micro-scale level have also been proposed including Gadow's differentiation index (Gadow, 1993; Gadow and Hui, 1999), which extends the nearest neighbour methods to the vertical structure analysis, and the structure complexity index (SCI) constructed by Zenner and Hibbs (2000), based on the distance between the tops of neighbouring trees. Choosing the right scale at which to calculate these indices is important and must always be taken into account when interpreting the results.

Much of the recent research has focused on stand structure in managed forests (Ferris-Kaan et al., 1998; Grassi et al., 2004; Kuuluvainen et al., 1996), although this area of study has not been adequately explored in Mediterranean forests. Silvicultural treatments are a key factor in stand structure (Franklin et al., 2002; Montes et al., 2005). Heterogeneity and complexity are often greater in natural stands than in man- aged ones (Hansen et al., 1991; Swanson and Franklin, 1992), and this has implications for species habitat availability. Scots pine (Pinus sylvestris $\mathrm{L}$.) is a boreal forest species that covers approximately 28 million ha in Europe and north-west Asia (Mason and Alía, 2000) and at the Southern limit of its distribution area can be found in Mediterranean mountain systems. Because of its broad distribution area and importance in the timber industry, it is a useful species for comparing regions in the Northern Hemisphere.

The primary aims of our study were: (1) to characterize the vertical structure of Scots pine stands at different stages in their development and the altitudinal gradient of the species occurrence through height complexity measures; (2) to evaluate a new index comparing vertical forest structure; and (3) to test two hypotheses: (a) uneven-aged stands display greater structural diversity than the respective even-aged stands, and (b) stand structure diversity within the even-aged stands is related to the silvicultural system employed and to the developmental stage.

\section{MATERIAL AND METHODS}

\subsection{Experimental site and data collection}

The data used in this study come from two managed Scots pine forests, Pinar de Valsain and Pinar de Navafría, located on the Northern slopes of the Sierra de Guadarrama, in the central mountain range in Spain. The altitude of both Scots pine forests ranges from approximately 1200 to $2200 \mathrm{~m}$, and the altitudinal position of the timberline is around $1800 \mathrm{~m}$ in both forests. Annual rainfall exceeds $730 \mathrm{~mm}$ and mean annual temperature is around $9.9^{\circ} \mathrm{C}$. These mountains are composed of granite and gneiss, with fairly homogeneous soils throughout the pinewoods, being predominantly humic cambisol type soils or leptosols at the higher sites (Forteza et al., 1988) according to the FAO taxonomic soil classification of 1989. The site index of these stands ranges between 21.4 and $29.9 \mathrm{~m}$ (Montes et al., 2007).

The management plans for both forests date from the end of the 19th century although there are certain differences between the two such as the regeneration periods considered, the thinning intensities and whether or not the herbaceous layer was removed to enhance regeneration. Today, the uniform shelterwood system is used in Navafría and the group shelterwood system is applied in Valsaín. These methods are applied with the objective of inducing natural regeneration and artificial regeneration is only employed in exceptional circumstances as a supplementary measure or aid. The existing stand is gradually removed so that tree seedlings become established under the protection of the older trees (Loftis, 1990). In Valsain the mature crop is gradually felled over a 40-year period while in Navafría the period is $20 \mathrm{y}$, with soil preparation being required to obtain natural regeneration. Thinning is either from below (removing subcanopy trees) or mixed (removing dominated and co-dominant trees) and the intensity is moderate. Such thinning is not normally initiated until the stand is between 20 and 40 years old, at which point, up to $40 \%$ of the basal area is removed without causing a loss in productivity.

Some areas of the Valsain forest are managed, uneven-aged stands, where selective cuttings are performed to remove large as well as damaged and diseased trees. This silvicultural system is employed in certain areas with low timber production $\left(0.5\right.$ to $\left.1.5 \mathrm{~m}^{3} \mathrm{ha}^{-1} \mathrm{y}^{-1}\right)$, on south-facing hillsides or zones that are exposed to wind and where 
Table I. Stand level variables in the experimental plots (extent 0.5 ha) in Navafría forest (N1, N2, N3, N4 and N5) and Valsaín forest (V1, V2, V3, V4, V5, V6, V7 and V8): Plot size $(\mathrm{m} \times \mathrm{m}$ ); Age class (years); $N \geq 7.5 \mathrm{~cm}$ and $N<7.5 \mathrm{~cm}$ (saplings), tree with DBH $\geq 7.5 \mathrm{~cm}$ and DBH $<$ $7.5 \mathrm{~cm}$ number per ha respectively with DBH being mean diameter at breast height $(\mathrm{cm})$ of tree; BA, basal area $\left(\mathrm{m}^{2}\right.$ ha $\left.{ }^{-1}\right) ; \mathrm{H}, \mathrm{mean}$ tree height (m) of the plot \pm standard deviation; $H$ max, maximum tree height of the plot; $H$ min, minimum tree height of the plot.

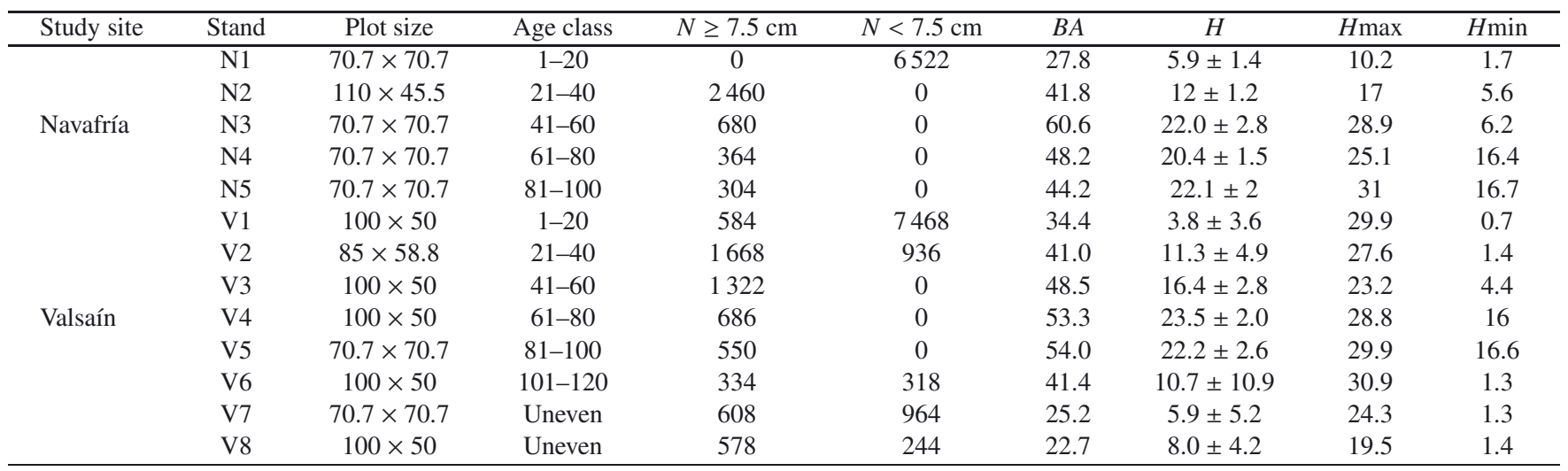

poor soils complicate natural regeneration. Stands at altitudes over $1600 \mathrm{~m}$ are also frequently managed under the same system because of the risk of wind and snow damage.

Five rectangular permanent sample plots were established at Navafría and eight in Valsaín (Tab. I). All of the plots were the same size ( 0.5 ha) enabling meaningful comparisons to be made regarding their structural diversity. These pure Scots pine plots include all the age classes which currently exist in the forests, which, in the case of Navafria (where rotation length is $100 \mathrm{y}$ and the regeneration period is $20 \mathrm{y}$ ) include age classes from 1-20 y up to 81-100 y. In Valsaín (where rotation length is $120 \mathrm{y}$ and the regeneration period is $40 \mathrm{y}$ ) the age classes include: 1-20 y, with sparse parent tree presence (plot V1) up to 101-120 y. Two plots, V7 and V8, were situated near the lower and upper elevation limits respectively of the Scots pine growth spectrum in the Valsain forest. Plot V7 was located at $1300 \mathrm{~m}$, where Scots pine was mixed with Pyrenean oak (Quercus pyrenaica Willd). Plot V8 was located at $1700 \mathrm{~m}$ near the altitudinal upper limit of Scots pine distribution in the central mountain range of Spain, where the stands are characterised by low tree density, a high protection factor and where the pinewood is gradually replaced by alpine shrubs (Juniperus comunis L. ssp. alpina and Cytisus oromediterraneous Rivas-Martínez).

The diameter at breast height $(D B H)$ and height $(H)$ were measured for all trees and the species identity was recorded for each. The stand variables calculated for each plot are presented in Table I. The position of all trees with $\mathrm{DBH}>7.5 \mathrm{~cm}$ were stem mapped while the positions of saplings (DBH below $7.5 \mathrm{~cm}$ ) were assigned to a $2 \times 2 \mathrm{~m}^{2}$ area (without exact coordinates) within a $2 \times 2 \mathrm{~m}^{2}$ grid placed over the plots.

\subsection{Vertical structure analysis}

\subsubsection{Non-spatially explicit indices of vertical structure diversity}

The vertical structure diversity of the stand was calculated using the Shannon index, which has been widely used in ecological studies and has proven to be a good indicator of the structural complexity of the forest (Kuuluvainen et al., 1996). The relative frequency (estimated through the number of trees within each height layer) can be substituted in the Shannon index for the proportion of basal area corresponding to each height class (Staudhammer and LeMay, 2001):

$$
\mathrm{H}^{\prime}=-\sum_{i=1}^{s} p_{\mathrm{i}} \ln p_{\mathrm{i}}
$$

where $s$ is the number of height classes at $5 \mathrm{~m}$ intervals (Tab. II) in the plot and $p_{\mathrm{i}}$ is the proportion of the basal area per ha of the $i$ th height class and the total basal area.

The standard deviation of tree height (SD) can be used as a straightforward index to assess structure that does not involve arbitrarily classified size classes (Tab. I). Height diversity was also calculated using the STVI structure index based on the variance of basal area per ha for height developed by Staudhammer and LeMay (2001), where the index for height is:

$$
\text { STVI }_{\mathrm{h}}=\left\{\begin{array}{lll}
1-\left(\frac{S_{\mathrm{hu}}^{2}-S_{\mathrm{h}}^{2}}{S_{\mathrm{hu}}^{2}}\right)^{p 1} & \text { when } & S_{\mathrm{h}}^{2} \leq S_{\mathrm{hu}}^{2} \\
1-\left(\frac{S_{\mathrm{h}}^{2}-S_{\mathrm{hu}}^{2}}{m \times S_{\mathrm{h} \max }-S_{\mathrm{hu}}^{2}}\right)^{p 2} & \text { when } & S_{\mathrm{h}}^{2}>S_{\mathrm{hu}}^{2}
\end{array}\right.
$$

with

$$
S_{\mathrm{h}}^{2}=\sum_{j=1}^{n} p_{\mathrm{j}}\left(H_{\mathrm{j}}-\bar{H}\right)^{2}
$$

where $S_{\text {hu }}^{2}$ is the variance of a uniform distribution, $S_{\mathrm{h} \max }^{2}$ the maximally bimodal distribution, and $S_{\mathrm{h}}^{2}$ is the sample variance.; $n$ is the number of trees in the sample, $p_{\mathrm{j}}$ is the ratio between the basal area of the $j$ th tree and the total basal area and $H_{\mathrm{j}}$ is the height of the $j$ th tree. The constants $p 1$ and $p 2$ are $>0$ and $m$ is $\geq 1: p 1$ and $p 2$ define the shape of the curve relating the value of the index to the sample variance while $m$ controls the value of the index when the distribution is maximally bimodal (LeMay and Staudhammer, 2005). These constants are constrained to equal certain values so that the index gives the largest value when the variance is generated according to a uniform distribution $\left(S_{\text {hu }}^{2}\right)$. Thus, STVI is standardized to be (i) 0.5: when the distribution is uniform over half of the total range and when the distribution is bimodal with half the values being uniformly distributed over the lower quartile and the other half uniformly distributed over the upper quartile; (ii) 0.1: for a distribution where 
Table II. Number $(N)$ of trees per height class in the $5 \mathrm{~m}$ interval classes $(N(0-5 \mathrm{~m})-N(30-35 \mathrm{~m}))$ considered for Shannon's index calculation in the experimental plots (extent 0.5 ha) in Navafría forest (N1, N2, N3, N4 and N5) and Valsaín forest (V1, V2, V3, V4, V5, V6, V7 and V8).

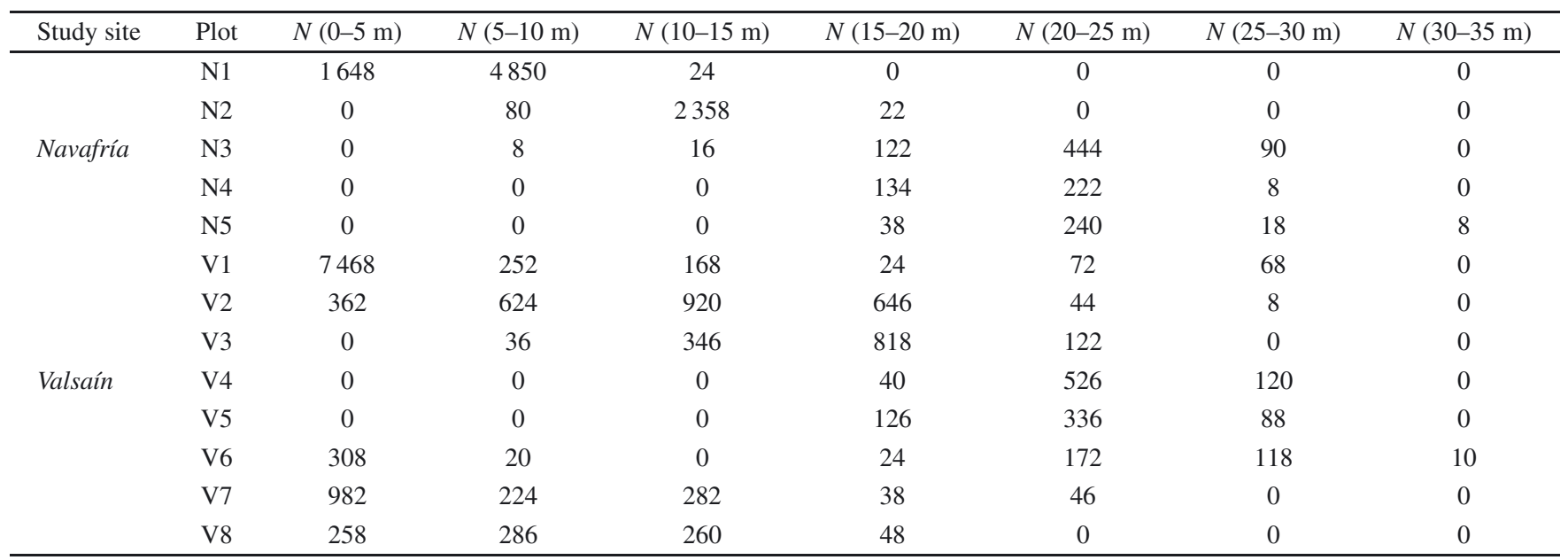

half of the values are equal to the lowest and half are equal to the highest (maximum variance), (see appendix of Staudhammer and LeMay (2001) for details). To define the variance of a uniform distribution and of the maximally bimodal distribution, we must define the range of the distribution given by $a$ and $b$. This interval must be the same in order to make comparisons between stands. Thus, STVI was calculated using an interval from $0(a)$ to $35(b) \mathrm{m}$ for each plot. The STVI index takes values between 0 (low diversity) and 1 (maximum diversity). The main advantages of STVI are: (1) that it gives the highest value when the variance is generated according to the uniform distribution, as with $\mathrm{H}^{\prime}$; (2) that there is no need to define classes; and (3) that although in this case it is used only for height, it allows the STVI for height, diameter and other variables to be combined. In this way, it can also be combined across species which would not be possible using other indices. However, there are also certain disadvantages to using STVI which include: (1) the need to define interval limits ( $a$, $b)$; (2) the fact that the STVI is more difficult to calculate than the variance alone.

To obtain an index similar to the Shannon index for continuous variables, the sum of the square root of the absolute difference between each value and the mean would be preferable to the sum of squares, because the square root does not have an exponential growth since the value of the differences increases. Therefore, we propose the following index, based on the sum of the square root of the difference (SQRI):

$$
\mathrm{SQRI}=\sum_{i=1}^{n} p_{\mathrm{j}} \sqrt{\left|H_{\mathrm{j}}-\bar{H}\right|}
$$

where the meaning of the symbols is the same as in equation (2).

Down-weighting larger differences by taking the square root make the distribution more similar to the natural logarithm used in Shannon index. While down-weighting did not lead to a great change in the values compared to those obtained considering only the absolute value of the differences, it did result in better correlations with both $\mathrm{H}^{\prime}$ and STVI. As with STVI, there is no need to define classes when using SQRI. Moreover, the latter is easier to calculate than STVI and it gives less weight than those based on variances. The main disadvantages are, on the one hand, that it increases the maximum $S_{\mathrm{h} \max }^{2}$ rather than $S_{\text {hu }}^{2}$ (as with STVI and $\mathrm{H}^{\prime}$ ), and on the other, that it cannot be combined across species or with other variables.

\subsubsection{Spatially explicit indices of vertical structural diversity}

The spatially explicit indices of vertical structure calculated can be used to give a picture of the height variability at a micro-scale, i.e., a tree and its neighbours. Gadow's differentiation index ( $\mathrm{DH} n)$ has been used to measure small-scale variability in the height size distribution. The $\mathrm{DH} n$ is given by:

$$
\mathrm{DH} n=\frac{1}{N} \sum_{s=1}^{N} \mathrm{DH} n s
$$

with

$$
\mathrm{DH} n s=\frac{1}{T} \sum_{t=1}^{T}\left(1-\frac{x \min }{x \max }\right)_{t}
$$

where $\mathrm{DH} n$ is the mean differentiation, $N$ the number of trees per plot and $\mathrm{DH} n_{s}$ the differentiation index for tree $s$ summed over $T$ pairs of neighbours, where $x_{\min }$ and $x_{\max }$ are the smallest and the largest height of tree pair $t$. Index values are possible between 0 and 1 . Values close to 0 indicate that the neighbours are of a very similar size, whereas values close to 1 reflect high differentiation. In this study three neighbours were included $\left(\mathrm{DH}_{3}\right)$, except for plot $N 1$. In this plot, all the trees were located in $2 \mathrm{~m} \times 2 \mathrm{~m}$ quadrats, so the differentiation index was calculated for all the trees within each quadrat (the mean tree number was 2.45 per quadrat) and averaged for the 0.5 ha plot.

Another index used to characterize the neighbourhood height differentiation is the structure complexity index (SCI) developed by Zenner and Hibbs (2000), based on the interaction between tree height and the spatial location of trees. Points marking the top of each three neighbouring trees are connected, constructing a 3-dimensional continuous tessellation of non-overlapping triangles (Fig. 1). This triangular irregular network satisfies the Delaunay criterion (Fraser and van den Driessche, 1971) (i.e., a circle drawn through the three nodes of a triangle contains no other point, the triangles are as equi-angular as possible and the triangulation is independent of the order in which the points are processed).

$$
\mathrm{SCI}=\frac{\sum_{i=1}^{M} \frac{1}{2}\left|a_{\mathrm{i}} \times b_{\mathrm{i}}\right|}{A_{\mathrm{T}}}
$$




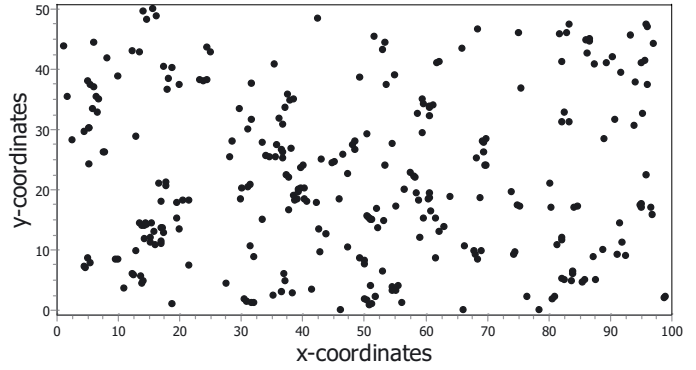

Figure 1. Tree distribution in V8 plot and triangular irregular network.

where $A_{\mathrm{t}}$ is the sum of the horizontal area covered by the triangles, $i=1 \ldots M$ is the number of triangles in the test plot, and $\frac{1}{2}\left|a_{\mathrm{i}} \times b_{\mathrm{i}}\right|$ represents the surface area of the triangles in 3-dimensions connecting $x, y$ and $z$ coordinates of trees (that represent the distance to origin with $z$ being the height of the tree) with $a$ and $b$ representing the base and height of each triangle. SCI is at its minimum when it is equal to one, i.e., when all the trees in the stand have the same height.

Indices accounting for tree positions require edge correction methods (Pommerening and Stoyan, 2006). To avoid this bias in the index calculations, we used the translation method to reduce the error both in Gadow's differentiation index and in the SCI. In the calculation of the latter, this omits very narrow and elongated triangles formed close to the edge of the plot which probably do not reflect true neighbours.

\subsection{Optimal plot size}

In order to determine the most appropriate sample size for evaluating vertical structure diversity in this type of forest, the three nonspatially explicit indices ( $\left.\mathrm{H}^{\prime}, \mathrm{STVI}, \mathrm{SQRI}\right)$ and the SCI spatially explicit index were calculated at different scales. We divided each plot into sub-plots of decreasing size to show how the height diversity varied with the size of the plot. The final index for each plot was then obtained by calculating the index for each subplot and taking the mean value in order to obtain a smoother resultant curve. To make sure that the estimates obtained for each plot size were accurate and unbiased we calculated the root mean square error (RMSE) and the bias relative to the correct index value and these were then plotted against the plot size:

$$
\begin{aligned}
\text { Bias } & =M-\hat{M} \\
\text { RMSE } & =\sqrt{\frac{1}{n-1} \sum_{k=1}^{n}\left(\hat{M}_{\mathrm{k}}-M\right)^{2}}
\end{aligned}
$$

where $\hat{M}$ is the estimate of the correct index value, $M$ is the correct index value and $n$ is the number of replications, in this case equal to the number of subdivisions.

\subsection{Correlation between indices}

Pearson's correlation coefficient was used as a measure of relationships among all the indices calculated for the final sample size of 0.5 ha. The analyses were performed using SAS 9.1 (SAS Institute Inc., 2004).
Table III. Vertical structure indices in the experimental plots in Navafría forest (N1, N2, N3, N4 and N5) and Valsaín forest (V1, V2, V3, V4, V5,V6,V7 and V8): H', Shannon's index; STVI, structure index based on the variance; SQRI, structure index based on the sum of square roots; DH3, Gadow's index for height and 3 neighbours; SCI, structure complexity index.

\begin{tabular}{ccccccc}
\hline Study site & Plot & $\mathrm{H}^{\prime}$ & STVI & SQRI & DH3 & SCI \\
\hline \multirow{5}{*}{ Navafría } & N1 & 0.37 & 0.08 & 1.03 & 0.13 & \\
& N2 & 0.24 & 0.06 & 0.91 & 0.07 & 1.46 \\
& N3 & 0.87 & 0.22 & 1.27 & 0.08 & 1.49 \\
& N4 & 0.71 & 0.08 & 0.99 & 0.06 & 1.05 \\
& N5 & 0.7 & 0.15 & 1.14 & 0.06 & 1.11 \\
& V1 & 1.55 & 0.64 & 2.7 & 0.19 & 2.8 \\
& V2 & 1.21 & 0.38 & 1.63 & 0.13 & 2.03 \\
& V3 & 0.93 & 0.23 & 1.34 & 0.12 & 1.75 \\
& V4 & 0.73 & 0.13 & 1.12 & 0.07 & 1.37 \\
& V5 & 0.59 & 0.24 & 1.35 & 0.07 & 1.25 \\
& V6 & 0.89 & 0.27 & 1.45 & 0.07 & 1.23 \\
& V7 & 1.34 & 0.97 & 2 & 0.17 & 1.73 \\
& V8 & 1.06 & 0.43 & 1.5 & 0.25 & 1.81 \\
\hline
\end{tabular}

\section{RESULTS}

Regarding the size of the plot chosen (i.e., $5000 \mathrm{~m}^{2}$ ), it can be observed that in all the cases studied the curve flattens off well within the plot size chosen, suggesting that a plot size of $1500 \mathrm{~m}^{2}$ would have been sufficient to obtain a reasonable estimate of diversity (Fig. 2). Mean values were lower when plot sizes were $<1500 \mathrm{~m}^{2}$ due to the increasing number of zero values obtained at smaller scales. Regarding the RMSE and Bias statistic performance, it seems that $1500 \mathrm{~m}^{2}$ may also be the smallest plot size if accurate and unbiased estimates of diversity are to be obtained (See Supplementary material available online only at www.afs-journal.org). As expected, the accuracy decreases and the bias increases when we reduce the plot size, especially in the most heterogeneous plots (V1 and V7) at the Valsain forest (See Supplementary material available online only at www.afs-journal.org).

The highest values obtained for the vertical structure diversity indices in the case of most of the indices examined correspond to the uneven-aged plots V7 (mixed Scots pinePyrenean oak stand) and V8 (Scots pine stand near the timberline) and to the even-aged Scots pine plots at the Valsain forest V1 and V2 (0-20 and 21-40 years respectively) where regeneration fellings have been carried out (Tab. III). 

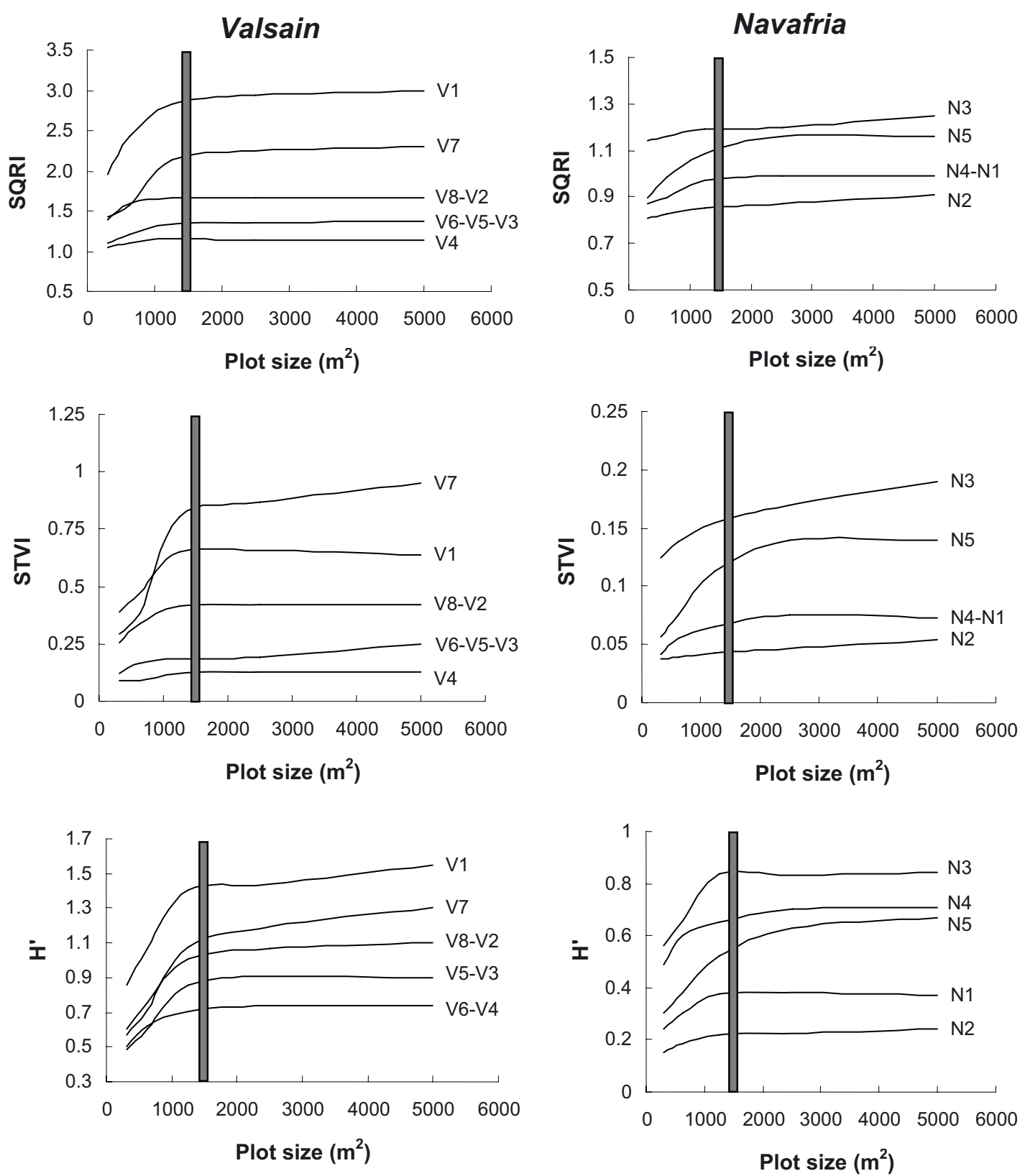

Figure 2. Value of the non-spatially explicit indices (SQRI, STVI and $\mathrm{H}^{\prime}$ ) in Valsaín and Navafría forests in relation to the plot size. Plots with very coincident values are grouped to make the graph clearer. A grey line is drawn in the graph when the plot size is equal to $1500 \mathrm{~m}^{2}$.

The change in vertical structure diversity indices for each forest over the life of the stands is shown in Figure 3. For almost all developmental stages, the indices showed higher values in Valsain than in Navafría. In the Navafría forest, $\mathrm{H}^{\prime}$ was lower for the younger plots ( $\mathrm{N} 1$ and N2) than for plots $\mathrm{N} 3, \mathrm{~N} 4$ and $\mathrm{N} 5$, due to the lower height of the trees and the high homogeneity of the young crop, which results in a reduced amount of vertical strata occupation. In Valsaín, a decreasing trend in $\mathrm{H}^{\prime}$ was evident over the life of the stand, with the exception of the oldest plot (V6), where a slight increase was observed. This situation in plot V6 was due to the fact that regeneration fellings had led to a spatial structure in which established regeneration appeared close to some of the parent trees. The new index, SQRI, was relatively constant in Navafría, whilst in Valsain it was more variable, with higher values in the younger stages. In Valsain the vertical differentiation shows a decreasing trend over the life of the stand although an increase was again observed in the oldest age class. In Navafría, this decreasing trend is less evident for some of the indices due to the high homogeneity of the young crop. $\mathrm{DH}_{3}$ and SCI show a different pattern over time for the older age classes in comparison with the rest of the indices and they 
a

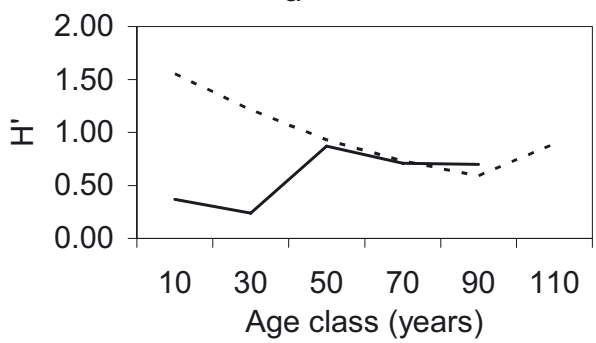

C

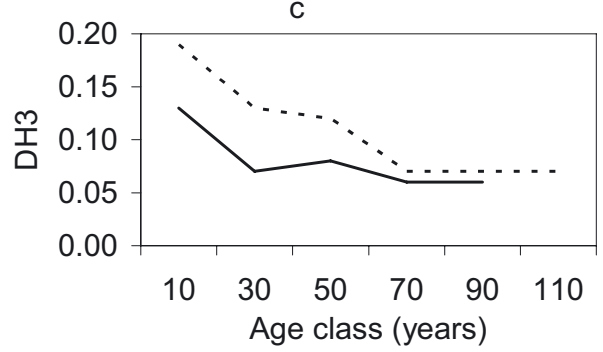

e

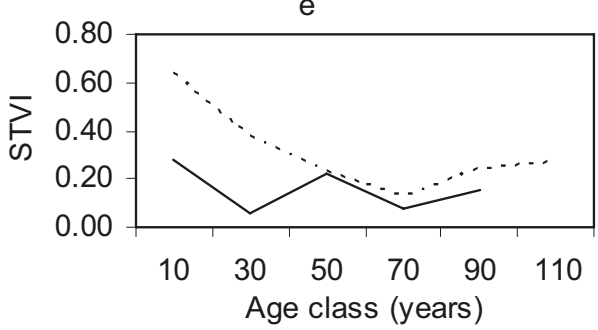

b

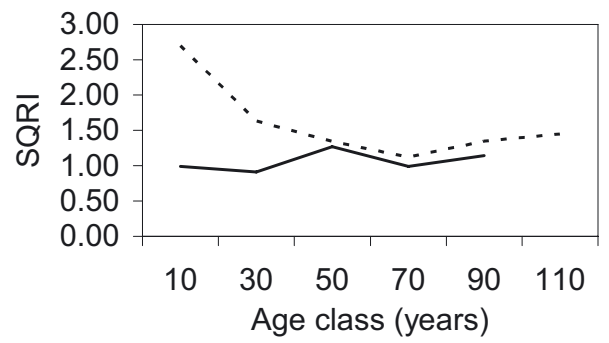

d

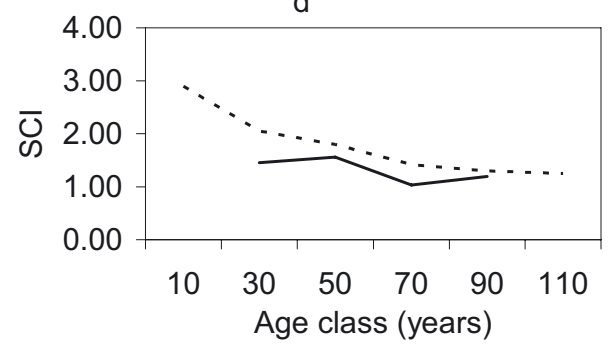

Figure 3. Evolution across the chronosequence of the vertical structure indices in Valsaín (dots) and Navafría (continuous line): (a) Shannon's index $\mathrm{H}^{\prime}$; (b) structure index based on the sum of square roots of differences in tree heights SQRI; (c) Gadow's index for height and 3 neighbours DH3; (d) structure complexity index, SCI; (e) structure index based on the variance of tree height, STVI.

flatten out when the stand reaches the stem-exclusion stage (at an age between 60-80 y). The plots located at the upper (V8) and lower (V7) limits of the distribution area of the species showed high values for all the analysed vertical structure diversity indices (Tab. III).

Correlations were significant between all the non-spatially explicit indices analyzed $(\alpha=0.01)$, except for the correlation between $\mathrm{H}^{\prime}$ and STVI, which was found to be significant at a level of 0.05 (Tab. IV). Correlations with the standard deviation of tree heights (SD) were also found to be significant for all indices except for $\mathrm{DH}_{3}$ (Tab. IV).

The behaviour of the analysed non-spatially explicit indices is expected to be similar because $\mathrm{H}^{\prime}$ depends on the number of height class intervals, and will have lower values for a fixed class interval in those plots that have a lower mean height, whereas STVI and SQRI values also depend on the mean height of each plot. The correlation between the spatially explicit indices $\mathrm{DH}_{3}$ and SCI was also significant $(\alpha=0.01)$. The results also showed a highly significant correlation between the spatially explicit and non-spatially explicit indices as well. In the case of the non-spatially explicit indices, the STVI index shows the highest correlation with Gadow's spatially explicit differentiation index. The SQRI is that which best correlates with SCI.
Table IV. Correlation matrix of the vertical structure indices for the final sample size of 0.5 ha: $\mathrm{H}^{\prime}$, Shannon's index; STVI, structure index based on the variance; SQRI, structure index based on the sum of square roots; DH3, Gadow's index for height and 3 neighbours; SCI, structure complexity index; SD, standard deviation of tree heights (Tab. I).

\begin{tabular}{lcccccc}
\hline & $\mathrm{H}^{\prime}$ & STVI & SQRI & DH3 & SCI & SD \\
\hline $\mathrm{H}^{\prime}$ & 1 & & & & & \\
STVI & $0.8300^{*}$ & 1 & & & & \\
SQRI & $0.8964^{* *}$ & $0.8382^{* *}$ & 1 & & & \\
$\mathrm{DH} 3$ & $0.6229^{*}$ & $0.6621^{*}$ & $0.6280^{*}$ & 1 & & \\
$\mathrm{SCI}$ & $0.7718^{* *}$ & $0.6109^{* *}$ & $0.8596^{* *}$ & $0.7326^{* *}$ & 1 & \\
$\mathrm{SD}$ & $0.8409^{* *}$ & $0.8101^{* *}$ & $0.7231^{* *}$ & 0.4751 & $0.5594^{*}$ & 1 \\
\hline
\end{tabular}

* Indicates significant correlation at 0.05 level and ** indicates significant correlation at 0.01 level.

All indices consistently gave the highest values to the uneven-aged plots (V7 and V8) as had been hypothesized, as well as to V1 (where regeneration fellings had begun) in the Valsain forest. Plot N3 (41-60 year age class) had the highest values of all successional stages in the Navafria forest (Fig. 4). The last age classes in Valsaín (V5 and V6) and Navafría (N4 and N5) had similar values for all indices (Fig. 4). 


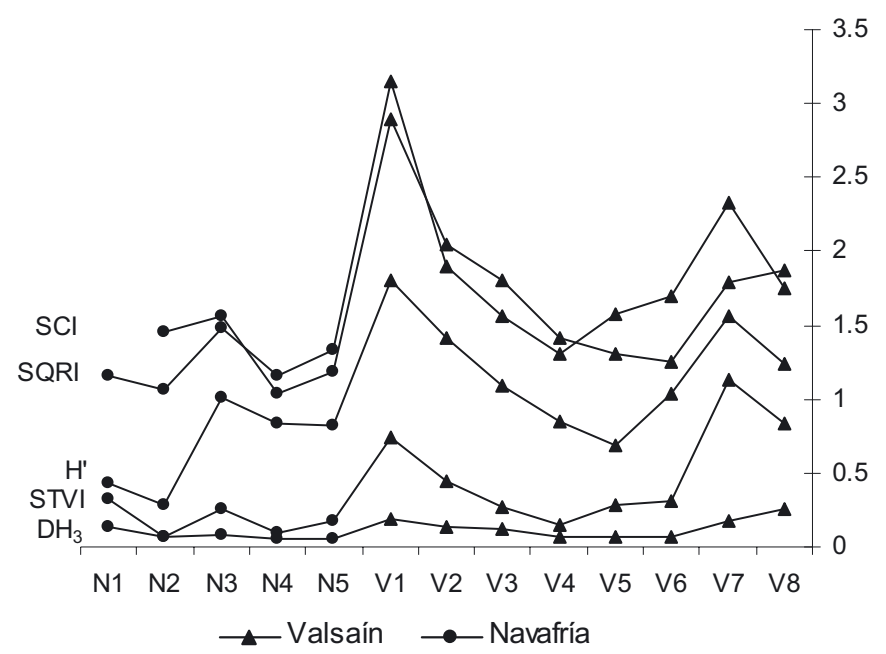

Figure 4. Value of the spatially and non-spatially explicit indices (SQRI, STVI, $\mathrm{H}^{\prime}, \mathrm{SCI}$ and $\mathrm{DH}_{3}$ ) in Valsaín (V1-V8) and Navafría (N1-N5) forests.

\section{DISCUSSION}

Several indices were used to characterize the development of vertical structure over time. Determining whether or not the vertical structure of one stand is more diverse than another may depend on the choice of diversity measure (Magurran, 1988). In this study all indices calculated showed similar values. The high correlation between indices can be explained by the structural homogeneity of the stands (due to current management practices) as well as the size of the study plots used.

The choice of plot size would appear to be adequate in all cases since the indices reach their asymptote within the 0.5 ha plot size chosen for the study. Therefore, we can be reasonably confident that the diversity measured by the different indices chosen has been captured (Magurran, 1988). In fact, the plots could have been reduced to about one-fourth of the size (i.e., 1000 to $2000 \mathrm{~m}^{2}$ ) in most of the stands without affecting the results obtained for the different indices, which would still have been accurate and unbiased. Plot size partly explains the strong correlation between the distant independent and dependent indices, given that the latter give a picture of diversity at smaller scales.

The use of indices based on the variance, such as STVI (Staudhammer and LeMay, 2001), can be advantageous because the values of these indices do not depend on setting artificial class boundaries. There is no general agreement on how many classes should be used when we calculate $\mathrm{H}^{\prime}$ or the sensitivity of the index to a change in the class width (Ferris-Kaan et al., 1998; Varga et al., 2005), hence, the optimal class width needs to be tested. Alternatively, Pretzsch (1995) proposed a vertical extension of the Shannon index based on a stratification of the vertical canopy layer into three relative strata representing $0-50,50-80$ and $80-100 \%$ of stand maximum height, respectively (Pretzsch et al., 2006). This approach, however, may not be applicable in relatively homogenous stands like the ones assessed in this study, where there are often only two strata, leading to the same index value for stands with different maximum heights and different structure (Weber, 2000). In contrast, STVI behaves like $\mathrm{H}^{\prime}$, in that it is maximum when the distribution is uniform over the basal area, when all the classes are evenly represented (Magurran, 1988) and avoids the problem of the Shannon and Pretzsch indices that require dividing the continuous variable into arbitrary classes. Moreover, the STVI gave good results that can be easily interpreted (Staudhammer and LeMay, 2001), although it is somewhat more complex to compute than other indices and involves the definition of a single range of distribution limits for all stands to enable stand comparisons. The SQRI index proposed in this study is based on the sum of the square roots of absolute height differences, so the magnitude of the differences between values for the variable has less weight in the index value than if the differences are squared. Also, the number of values that are different acquires more importance in the index value than the magnitude of the differences.

Gadow's differentiation index has been used for the structural characterization of forests (Aguirre et al., 2003), and because it quantifies height variability between neighbouring trees, it may prove to be a useful tool for analysing the relationship between structure, competition and silvicultural applications (Montes et al., 2004). The differentiation index values in the plots with dense regeneration in both forests $(N 1=0.13 ; V 1=0.19)$ are similar to the values of $0.12-0.13$ found by Kint (2005) in former homogeneous Scots pine plantations where no management practices are currently allowed. However, in the latter study, the differentiation index values for the pine stands without regeneration $(0.17-0.24)$ and for the mixed pine-oak stands $(0.23-0.33)$ he found are considerably higher than those found in our stands. The SCI index is mainly influenced by the micro-scale vertical structure, keeping a very constant value independent of the sample size chosen (results not shown). SCI values are very low in Navafria (1.02-1.52) indicating that these stands are extremely homogeneous, while in Valsain only the 0-20 multi-storied stand where regeneration develops in conjunction with the parent trees presents a significantly higher value than the rest of the plots. SCI decreases throughout the rotation as most of the indices calculated, behaving in a different way to natural forests where the older stands exhibit a higher degree of small-scale variation (Zenner, 2004; 2005). Both $\mathrm{DH}_{3}$ and SCI reveal a different pattern in the oldest age classes than the rest of the indices; levelling off instead of increasing. This probably indicates a clustered pattern of trees of similar heights in these age classes which is not detected by the non-spatially explicit indices. Although they have a lot of potential in practical studies, the disadvantage associated with spatial indices such as SCI and Gadow's differentiation index is that they can be more expensive and time consuming since the position of the trees has to be determined. Furthermore, the different scales could be better separated using second-order characteristics that consider the interaction of pairs of trees at pre-defined inter-tree distances rather than using neighbourhood based spatial indices. However, this would require an even greater number of tree positions to be calculated. When mapped data are available, marked point processes can be used as an alternative to 
study the vertical diversity (Montes et al., 2008). The high correlations between the spatially explicit and the spatially nonexplicit indices in this study indicate that in structurally homogeneous stands such as these, the additional assessment of the nearest neighbours does not provide much additional information regarding stand structure. This contrasts with the additional information provided by spatially explicit indices in more heterogeneous plots (e.g. Sterba, 2008).

The STVI, SQRI, $\mathrm{DH}_{3}$ and SCI in general showed lower values in the Navafría forest than in Valsain (Fig. 3), as a consequence of the more intensive thinning regime and the shorter regeneration period (often using soil tillage) in Navafría. However, the $\mathrm{H}^{\prime}$ does not show this trend for the mature stages, probably because the choice of height class exerts a great influence on the value of this index. The index will thus be influenced by the fact that there are the same or even a higher number of classes in Navafría than in Valsaín even if there are very few trees in some of the classes in Navafría. The relationship between succesional stage and structure diversity changed in different ways with increasing age, depending on the different indices used. Similar results were found by Varga et al. (2005). In our case, both forests show a decrease in structural diversity over the life of the stand according to most of the indices. However, in Navafría the high homogeneity of the young crop combined with a very low density of seed trees results in a reduced amount of vertical strata occupation in the two first age classes ( $N 1$ and $N 2$ ) which gives very low values for some of the indices. The results of the stands studied contrast with many natural or semi-natural stands investigated that show increasing complexity as the stands mature and develop towards old-growth with greater numbers of diameter classes (Kint, 2005; O'Hara et al., 2007; Zenner, 2004). However, this can be partly explained by the management practices that have taken place in these stands. Thinning from below, which involves the removal of the weakest and most malformed individuals from the dominated and co-dominated strata, reduces the range and standard deviation of tree heights. The decrease in stand diversity associated with thinning from below confirms the findings reported by Lähde et al. (1999) and Pretzsch (1995) in earlier studies.

The behaviour of the structural indices in the uneven-aged plots V7 and V8 was different from the other plots, as had been hypothesized. Similarly, earlier studies identified higher structural indices values in uneven-aged forest stands (Coates and Steventon, 1995; Jaehne and Dohrenbush, 1997). Varga et al. (2005) found that structural diversity was higher in mixedspecies stands than in single-species stands for the majority of the cases they studied. Our results also suggest the same trend for Valsain forest. Mixed plot (V7), in the ecotone between the pinewood and the broadleaved forest, presents a two-storied canopy layer that showed higher diversity values than almost all of the pure Scots pine stands studied. This contrasts with the tendency of pines to form mono-layered even-aged stands under the current management regime. The low density and frequent disturbances by snow and windthrow in plot V8, located near the timberline, favour a cluster structure with high height heterogeneity as found in other coniferous formations near the altitudinal tree line (Camarero et al., 2000). There- fore, this plot is amongst those with the highest values for all the indices studied. Non-spatially explicit indices show higher values in plot $\mathrm{V} 7$ but spatially explicit indices $\left(\mathrm{DH}_{3}\right.$ and $\left.\mathrm{SCI}\right)$ are higher in V8 than in V7. This can be attributed to the fact that the oaks, which tend to form clusters since most stems are of sprout origin, exclude the pines. As a consequence, every oak or pine is normally surrounded by trees of the same species with a similar height, leading to smaller values for the indices in the mixed Scots pine-oak stand than in the plot near the timberline.

\section{CONCLUSIONS}

The height diversity indices analysed in this study can be used to compare or monitor height structure complexity. The new index proposed (SQRI) might be considered an alternative for the evaluation of forest structure diversity. However, further comparisons with indices used in other investigated stands or through modelled stands with known properties are needed to test the behaviour of the index devised in this paper. In the structurally homogeneous stands included in this study, correlations among indices were very high. Based on the results of this study, it seems that the succesional stage must be considered when evaluating vertical structure diversity in managed even-aged stands since structural complexity is highly related to the silvicultural practices that are carried out at different ages. Thinning from below accounted for the decrease in vertical structure complexity throughout the rotation period as the range and the standard deviation of tree heights were reduced as a result of management practices. The results obtained in this study have implications for forest managers since the practices which give rise to longer regeneration periods in even-aged stands, such as those applied in the Valsaín forest, seem to increase structural diversity throughout the whole rotation period.

Acknowledgements: The authors thank Ángel Bachiller, Estrella Viscasillas and Enrique Garriga for their help in the field work, Valerie LeMay, Guillermo Gea-Izquierdo and Veronica Lo for useful discussions on earlier versions of the manuscript, Adam Collins for language revision, and two anonymous reviewers for their valuable comments. This study has been funded through the project AGL2004-07094.CO2.01/FOR of the Spanish Ministry of Education and Science.

\section{REFERENCES}

Aguirre O., Hui G.., Gadow K.V., and Jiménez J., 2003. An analysis of spatial forest structure using neighbourhood-based variables. For. Ecol. Manage. 183: 137-145.

Berger A. and Puettmann K.J., 2000. Overstory composition and stand structure influence herbaceous plant diversity in the mixed aspen forest of northern Minnesota. Am. Midl. Nat. 143: 111-125.

Buongiorno J., Dahir S., Lu H.C., and Lin C.R., 1994. Tree size diversity and economic returns in uneven-aged forest stands. For. Sci. 40: 83-103.

Camarero J.J., Gutiérrez E., Fortin M.J., and Ribbens, E. 2005 Spatial patterns of tree recruitment in a relict population of Pinus uncinata: forest expansion through stratified diffusion. J. Biogeogr. 32: 1979-1992. 
Coates, K.D. and Steventon J.D., 1995. Patch retention harvesting as a technique for maintaining stand level biodiversity in forests of north central British Columbia. In: Bamsey S.R. (Ed.), Innovative silviculture systems in Boreal forests, Proc. IUFRO Symp. in Edmonton, Alberta, Canada, 2-8 October 1994, pp. 102-106.

Dale M.R.T., 1999. Spatial pattern analysis in plant ecology, Cambridge University Press, Cambridge, 326 p.

FAO, 1989. Carte mondiale des sols - légende révisée, FAO, Rapport sur les ressources en sols du monde, No. 60, Rome.

Degraaf R.M., Hestbeck J.B., and Yamasaki, M., 1998. Associations between breeding bird abundance and stand structure in the white mountains, New Hampshire and Maine, USA. For. Ecol. Manage. 103: 217-233.

Ferris-Kaan R., Peace A.J., and Humphrey, J.W., 1998. Assesing structural diversity in managed forests. In: Bachmann, P. (Ed.), Assesment of biodiversity for improved forest planning, European Forest Institute Proceedings, 18, Kluwer Academic Publishers, Dordrecht, the Netherlands, pp. 331-342.

Forteza J., Lorenzo L.F., Najac N., Cuadrado S., Ingelmo F., Hernández J., García M.P., Prat L., Muñez M.C., Macarro M.C., Rivas M.D., and García, A., 1988. Mapa de suelos de Castilla León, escala 1:500 000, Consejería de Fomento, Junta de Castilla y León, Valladolid.

Franklin J.F., Spies, T.A., Pelt R.V., Carey A.B., Thornburgh D.A., Berg D.R., Lindenmayer D.B., Harmon M.E., Keeton W.S., Shaw D.C., Bible K., and Chen J., 2002. Disturbances and structural development of natural forest ecosystems with silvicultural implications, using Douglas-fir forests as an example. For. Ecol. Manage. 155: 399-423.

Fraser A.R. and van den Driessche, P., 1971. Triangles, density, and pattern in plant point populations. In: Proceedings of the 3rd conference Advisory Group of Forest Statisticians, Int. Union. For Res. Organ., Inst. Nat. Rech. Agric., Jouy-en-Josas, France, pp. 277-286.

Gadow K.V., 1993. Zur Bestandesbeschreibung in der Forsteinrichtung. Forst und Holz 21: 601-606.

Gadow K.V. and Hui G., 1999. Modelling forest development, Kluwer academic publishers, Dordrecht, the Netherlands, $213 \mathrm{p}$.

Grassi G., Minotta G., Tonon G., and Bagnaresi U., 2004. Dynamics of Norway spruce and silver fir natural regeneration in a mixed stand under uneven-aged management. Can. J. For. Res. 34: 141-149.

Hansen A.J., Spies T.A., Swanson F.J., and Ohmann J.L., 1991. Conserving biodiversity in managed forests: lessons from natural forests. Bioscience 41: 382-392.

Jaehne S. and Dohrenbush A., 1997. Ein Verfahren zur Beurteilung der Bestandesdiversität. Summary: A method to evaluate forest stand diversity. Forstw. Cbl. 116: 333-345.

Kimming J.P., 1997. Biodiversity and its relationship to ecosystem health and integrity. For. Chron; 73: 229-232.

Kint V., 2005. Structural development in ageing temperate Scots pine stands. For. Ecol. Manage. 214: 237-250.

Kuuluvainen T., Penttinen A., Leionen K., and Nygren M., 1996. Statistical opportunities for comparing stand structural heterogeneity in managed and primeval forests: an example from boreal Spruce forest in southern Finland. Silva Fenn. 30: 315-328.

Lähde E., Laiho O., and Norokorpi Y., 1999. Diversity-oriented silviculture in the boreal zone of Europe. For. Ecol. Manage. 118: 223-243.

LeMay V. and Staudhammer C., 2005. Indices of stand structural diversity: adding spatial diversity to a stand structural index. Extended abstract. In: Proceedings of the IUFRO Sustainable Forestry in Theory and Practice: Recent Advances in Inventory and Monitoring Conference, Edinburgh, Scotland.

Loftis D.L., 1990. A Shelterwood method for regenerating red oak in the southern Appalachians. For. Sci. 36: 917-929.

MacArthur R.M. and Mac Arthur J.W., 1961. On bird species diversity. Ecology 42: 594-598.

Magurran A.E., 1988. Ecological diversity and its measurement, Princeton University Press, Princeton, New Jersey, 179 p.

Mason W.L. and Alía R., 2000. Current and future status of Scots pine (Pinus sylvestris L.) forests in Europe, Investigación Agraria,
Sistemas y recursos forestales, Fuera de serie No. 1: 318-333.

Miller T.F., Mladenoff D.J., and Clayton M.K., 2002. Old-growth northern hardwood forests: spatial autocorrelation and patterns of understory vegetation. Ecol. Monogr. 72: 487-503.

Moen C.A. and Gutiérrez R.J., 1997. California spotted owl habitat selection in the central Sierra Nevada. J. Wild. Manage. 61:1281-1287.

Montes F., Cañellas I., Río M.d.., Calama R., and Montero G., 2004. The effects of thinning on the structural diversity of coppice forests. Ann. For. Sci. 61: 771-779.

Montes F., Sánchez M., Río M.d., and Cañellas I., 2005. Using historic management records to characterize the effects of management on the structural diversity of forests. For. Ecol. Manage. 207: 279-293.

Montes F., Pita P., Rubio A., and Cañellas I., 2007. Leaf area index estimation in mountain even-aged Pinus silvestris $L$. stands from hemispherical photographs. Agric. For. Meteorol. 145: 215-228.

Montes F., Barbeito I., Rubio A., and Cañellas I., 2008. Evaluating height structure in Scots pine forests using marked point processes. Can. J. For. Res. 38: 1924-1934.

Neumann M. and Starlinger F., 2001. The significance of different indices for stand structure and diversity in forest. For. Ecol. Manage. 145: 91-106.

North M.P., Franklin J.F., Carey A.B., Forsman E.D., and Hamer T., 1999. Forest stand structure of the northern spotted owl's foraging habitat. For. Sci. 45: 520-527.

O'Hara K.L., Hasenauer H., and Kindermann G., 2007. Sustainability in multi-aged stands: an analysis of long-term plenter systems. Forestry 80: $163-181$.

Pretzsch H., 1995. Zum Einfluss des Baumverteilungsmusters auf den Bestandeszuwachs. Allg. Forst-u. J. Ztg. 166: 190-201.

Pretzsch H., Utschig H., and Sodtke R., 2006. Applications of tree growth modelling in decision support for sustainable forest management. In: Hasenauer H. (Ed.), Sustainable forest management: growth models for Europe, Springer Verlag, Berlin Heidelberg, pp. 131-149.

Pommerening A. and Stoyan D., 2006. Edge-correction needs in estimating indices of spatial forest structure. Can. J. For. Res. 36: $1723-1739$.

Recher H.F., Majer J.D., and Ganesh S., 1996. Eucalyptus, arthropods and birds: on the relation between foliar nutrients and species richness, For. Ecol. Manage. 85: 177-195.

SAS Institue Inc., SAS OnlineDoc ${ }^{\circledR}$. Version 9.1.3, SAS Institute Inc., Cary, USA, 2004.

Shannon C.E., 1949. The mathematical theory of communication. In: Shannon C.E. and Weaver W. (Eds.), The mathematical theory of communication, University of Illinois Press, Urbana, IL, pp. 29-125.

Staudhammer C.L. and LeMay V.M., 2001. Introduction and evaluation of possible indices of stand structural diversity. Can. J. For. Res. 31: $1105-1115$.

Sterba H., 2008. Diversity indices based on angle count sampling and their interrelationships when used in forest inventories. Forestry 81: 587-597.

Swanson F.J. and Franklin J.F., 1992. New forestry principles from ecosystem analysis of pacific Northwest forests. Ecol. Appl. 3: 262-274.

Varga P., Chen H.Y.H., and Klinka K., 2005. Tree-size diversity between single- and mixed-species stands in three forest types in western Canada. Can. J. For. Res. 35: 593-601.

Zenner E. and Hibbs D., 2000. A new method for modelling the heterogeneity of forest structure. For. Ecol. Manage. 129: 75-87.

Zenner E., 2004., Does old-growth condition imply high live-tree structural complexity? For. Ecol. Manage. 195: 243-258.

Zenner E., 2005. Investigating scale-dependent stand heterogeneity with structure-area-curves. For. Ecol. Manage. 209: 87-100.

Weber J., 2000. Geostatistische analyse der struktur von waldbeständen am beispiel ausgewählter Bannwälder in Baden-Württemberg. Berichte freiburger forstliche forschung Heft 20, FVA BadenWürttemberg, Freiburg, 133 p. 